\title{
Relationship between NADPH and Th I/Th2 ratio in patients with non-Hodgkin lymphoma who have been exposed to pesticides
}

This article was published in the following Dove Press journal:

Journal of Blood Medicine

3I March 2015

Number of times this article has been viewed

\author{
Meriem Rabia Zahzeh' \\ Bouchra Loukidi' \\ Warda Meziane' \\ Mustapha Haddouche ${ }^{1,2}$ \\ Naima Mesli',3 \\ Zahia Zouaoui ${ }^{4}$ \\ Mourad Aribi' \\ 'Laboratory of Applied Molecular \\ Biology and Immunology, \\ ${ }^{2}$ Department of Medicine, University \\ of Tlemcen, Tlemcen, Algeria; \\ ${ }^{3}$ Department of Clinical Haematology, \\ Tlemcen Medical Centre University, \\ Tlemcen, Algeria; ${ }^{4}$ Department of \\ Clinical Haematology, Sidi Bel-Abbès \\ Medical Centre University, Sidi Bel- \\ Abbès, Algeria
}

\begin{abstract}
The effect of pesticides on nicotinamide adenine dinucleotide phosphate hydrogen (NADPH), including its level and relationship with the T helper 1 (Th1)/Th2 ratio, in patients suffering from non-Hodgkin lymphoma (NHL) was investigated. One hundred newly diagnosed patients with aggressive NHL (53 men, 47 women) and 40 healthy age-, sex-, and body mass index-matched controls (23 men, 17 women), exposed or not to pesticides, were recruited for a cross-sectional study conducted at the Clinical Hematology Departments of Tlemcen and Sidi Bel-Abbès University Medical Centers in the northwest of Algeria. NADPH levels were significantly increased in patients compared with controls; and in exposed patients compared with those not exposed, and controls (one-way analysis of variance; $P=0.000$ ). Albumin, glutathione peroxidase, superoxide dismutase, catalase activity, and oxygen radical absorbance capacity levels were significantly decreased in patients compared with in the control group. Oxygen radical absorbance capacity levels were significantly decreased in exposed patients compared with in unexposed patients; however, malondialdehyde levels were significantly increased in exposed patients when compared with controls and unexposed patients. Protein carbonyl and xanthine oxidase levels were significantly increased in exposed patients compared with controls; meanwhile, there were no significant differences between the two patient groups or between unexposed patients and controls. The Th1/Th2 ratio was significantly decreased in patients when compared with controls; the neutrophil-to-lymphocyte ratio was significantly increased (for both comparisons, $P<0.001$ ). In addition, NADPH was strongly associated with NHL (Mantel-Haenszel common odds ratio estimate $=5.55$; 95\% confidence interval, 2.22-13.88; $P=0.000$ ). Moreover, NADPH levels were significantly negatively related to the $\mathrm{Th} 1 / \mathrm{Th} 2$ ratio, either in exposed patients or in unexposed patients (respectively, $r=-0.498[P=0.004]$ and $r=-0.327[P=0.006])$. In conclusion, pesticide exposure was strongly associated with NADPH alteration in NHL. The relationship between NADPH and Th1/Th2 ratio should focus on new therapeutic strategies for the disease.
\end{abstract}

Keywords: non-Hodgkin lymphoma, pesticides, NADPH, Th1/Th2 ratio

\section{Introduction}

Non-Hodgkin lymphoma (NHL) includes several lymphoproliferative malignant diseases with different clinical and histological appearances. It can be present in various ways that are difficult to diagnose. NHL frequency has increased during the last 30 years. ${ }^{1}$ It is the fifth most common malignancy in the world and accounts for $5 \%$ of deaths related to cancer. ${ }^{2}$ In the majority of NHL cases, the cause has not been identified, although several factors have been involved in their pathogenesis, such as chronic antigenic stimulation, virus, immunosuppression, genetic, endogenous, and occupational factors, including pesticides. ${ }^{3} \mathrm{~A}$ strong association between pesticides and

\footnotetext{
Correspondence: Mourad Aribi Laboratory of Applied Molecular Biology and Immunology, Imama-Mansourah, Rocade \#2, Department of Biology, University of Tlemcen, 13000 Tlemcen, Algeria Tel +2I30556 28I 75I $\mathrm{Fax}+213040911082$

Email m_aribi@mail.univ-tlemcen.dz
} 
NHL has been previously reported. ${ }^{4}$ Recently, a French study has shown a relationship between occupational exposure to pesticides and the acquisition of a chromosomal abnormality known to cause the disease development. ${ }^{5}$

Nicotinamide adenine dinucleotide phosphate hydrogen (NADPH) is the reduced form of nicotinamide adenine dinucleotide phosphate (NADP), a coenzyme composed of ribosylnicotinamide $5^{\prime}$-phosphate (NMN) coupled by pyrophosphate linkage to the $5^{\prime}$-phosphate adenosine $2^{\prime}, 5^{\prime}$-bisphosphate. NADPH should be considered to be of major importance in the mitochondrial compartment. It fulfills this task both by scavenging toxic free radicals and repairing biomolecule-derived radicals, while serving as an electron carrier in numerous reactions. ${ }^{6}$

$\mathrm{NADPH}$ is mainly produced by four enzymes in mammalian cells: 6-phosphogluconate dehydrogenase, phosphogluconate dehydrogenase, malic enzyme, and cytoplasmic isocitrate dehydrogenase. Detoxification of reactive oxygen species (ROS) involves glutathione, which must be constantly regenerated by glutathione reductase. Thanks to this reaction, NADPH has been suggested to act as an indirectly operating antioxidant, and thus maintain the antioxidative power of gluthatione. ${ }^{6} \mathrm{NADPH}$ is known to play a vital role in energy metabolism and antioxidation. The antioxidant system depends on the production of NADPH for proper function.

The T helper 1 (Th1)/Th2 balance is defined by the homeostatic control of the immune system through the secretion of various cytokines. Tumor immunity is usually mediated by cytotoxic T lymphocytes, whose activation and stimulation are supported by Th1-type cytokines, as most clinical studies support the finding of an abnormal Th1/Th2 ratio in patients with cancer. ${ }^{7}$ Alterations of Th1 or Th2 cytokine profiles are usually characterized by a decreased $\mathrm{Th} 1 / \mathrm{Th} 2$ ratio and are described in virtually all tested patients with cancer, including those with NHL. ${ }^{8}$ Alterations of the Th1/Th2 ratio in patients with cancer is a common feature of a malignant process and could result from a malfunction in Th1 cells, activation of Th2 lymphocytes, or both phenomena.

Because NADPH has a role in a wide range of processes with potent antioxidant effects and because oxidative stress condition is high in malignant cells, we tried to demonstrate the relationship that may exist between NADPH and Th1/Th2 ratio in patients with NHL exposed to pesticides.

\section{Materials and methods}

\section{Patients and subjects}

One hundred newly diagnosed patients with aggressive NHL (53 men, 47 women) and 40 healthy age-, sex-, and body mass index-matched controls (23 men, 17 women), exposed or not to pesticides, were recruited for a cross-sectional study conducted at the Clinical Hematology Departments of Tlemcen and Sidi Bel-Abbès University Medical Centeres in the northwest of Algeria. The recruitment was made on the basis of a questionnaire. Participants exposed to pesticides (patients [ $n=32]$, age, 58.48 \pm 3.27 years; controls $[n=20]$, age, $56.12 \pm 2.93$ years) were selected from among farm workers to obtain a homogeneous population. Patients $(n=68$; age, $55.25 \pm 2.82$ years) and controls $(n=20$; age, $56.6 \pm 3.1$ years $)$ not exposed to pesticides had no history of occupational or environmental exposure to pesticides. To minimize bias, the clinical and demographic characteristics, pesticide exposure, duration of exposure to pesticides, and access to care were the same in all groups studied. Patients and controls were randomly selected on the basis of eligibility criteria from a group of 264 subjects (172 patients and 92 controls). Of 124 participants who were excluded, 72 patients ( 19 exposed to pesticides and 53 not exposed to pesticides) were eliminated because they did not meet the eligibility criteria. Of 45 participants in the exposed control group, 21 were excluded because of ineligibility and four were eliminated because they refused to participate. Of 47 unexposed controls, 20 subjects were randomly selected among those who fulfilled the eligibility criteria and agreed to participate in this study. Clinical presentation and characteristics of patients were recorded at recruitment. Histological examination and immunohistochemical analysis were complemented by a full and thorough mandatory clinical examination coupled with both expansion and biological assessments. The main criterion for inclusion was patients with aggressive NHL exposed or not to pesticides. The mainly exclusion criteria were NHL associated with another type of cancer, family history of cancer, indolent lymphoma, a positive serology for HIV, hepatitis C virus, and autoimmunity. All patients provided signed informed consent. This work was approved by our local institutional ethics committee (CSF-SBA).

\section{Samples}

Blood samples were taken from the antecubital vein and collected in ethylenediaminetetraacetic acid or heparin or in dry tubes. NADPH was determined on serum. Assays relating to oxidative stress were made on plasma for total antioxidant capacity (ORAC, oxygen radical absorbance capacity), lipid peroxidation (malondialdehyde), antioxidant enzymes (superoxide dismutase, glutathione peroxidase, and catalase; ethylenediaminetetraacetic acid), oxidative enzymes (xanthine oxidase), and oxidative protein (carbonyl protein; heparin). The cytokine levels were assayed on serum. 
The neutrophil-to-lymphocyte ratio (NLR) was determined from the whole blood. Lactate dehydrogenase (LDH) and alkaline phosphatase (ALP) were collected from the medical record for each individual.

\section{Laboratory assays $\mathrm{NADPH}$ assay}

Serum NADPH levels were measured spectrophotometrically at $450 \mathrm{~nm}$ by enzyme-linked immunoassay (ELISA), using a commercial kit (NADP/NADPH Quantification Kit, Sigma-Aldrich, St Louis, MO, USA). NADP was decomposed to detect NADPH according to the manufacturer's instructions. Samples were deproteinized before use in an assay, using a $10 \mathrm{kDa}$ spin filter. All measurements were performed in duplicate. Results were compared with the standard curve.

\section{NLR}

NLR was calculated using absolute neutrophil and lymphocyte counts recorded from total blood white cell count results within 24 hours after arrival to the hospital.

\section{Interleukin 4 and Interferon-gamma assays and $\mathrm{Th} \mathrm{I} / \mathrm{Th} 2$ ratio}

The serum interleukin 4 (IL-4) and interferon gamma (IFN-gamma) levels were measured by human Quantikine sandwich ELISA kits according to the instructions of the manufacturer (R\&D Systems GmbH, WiesbadenNordenstadt, Germany). Limits of detection were $8 \mathrm{pg} / \mathrm{mL}$ for IFN-gamma and $10 \mathrm{pg} / \mathrm{mL}$ for IL-4. The Th1/Th2 ratio was estimated from the IFN-gamma/IL-4 ratio.

\section{Albumin assay}

Serum albumin levels were carried out using a Sebia Hydragel Protein(e) K20 electrophoresis assay (Sebia, Evry, France).

\section{Glutathione peroxidase assay}

Glutathione peroxidase (GSH-Px) activity was measured according to the method of Paglia and Valentine, which relies on the spectrophotometric measurement at $340 \mathrm{~nm}$ from the oxidation of glutathione by cumenehydroperoxide. ${ }^{9}$

\section{Superoxide dismutase assay}

The assay of superoxide dismutase (SOD) was performed by a commercial kit (Randox Laboratories Ltd, Crumlin, United Kingdom). When SOD is found in the sample, it inhibits the production of formazan dye by the conversion of a superoxide radical to oxygen. This color is the result of the interaction between the salts of p-iodonitrotetrazolium [2-(4-iodophenyl)-3(4-notrophenol)-5-phenyltetrazolium chloride] and xanthine, as well as xanthine oxidase, to generate superoxide radicals. The SOD activity was then determined by spectrophotometry at $505 \mathrm{~nm}$.

\section{Catalase assay}

Catalase activity (CAT) was measured spectrophotometrically at $240 \mathrm{~nm}$ by monitoring the disappearance of $\mathrm{H}_{2} \mathrm{O}_{2}$, as described. ${ }^{10}$

\section{Total antioxidant capacity assay}

Total antioxidant capacity (ORAC) was measured in plasma according to the KRL (Spiral/KIRIAL, Dijon, France) biological test, based on the hemolysis resulting from the attack of radicals. ${ }^{11}$

\section{Malondialdehyde assay}

Analysis of lipid peroxidation was based on the determination of levels of malondialdehyde (MDA), using the thiobarbituric test. MDA react with thiobarbituric under high temperature and acidic conditions to give pink chromophores (MDA-TBA adduct) measured colorimetrically at $535 \mathrm{~nm} .^{12}$

\section{Protein carbonyl assay}

An ELISA was used to measure the concentrations of protein carbonyl on the basis of the detection of 2,4dinitrophenylhydrazine by the specific antibody (Biocell carbonyl protein ELISA kit, ALX-850-312-KI01; AXXORA Deutschland GmbH, Lörrach, Germany).

\section{Xanthine oxidase assay}

The enzymatic oxidation was represented by the measurement of xanthine oxidase (XO). It was determined by the level of uric acid formation from xanthine at $293 \mathrm{~nm}$, according to the method of Hashimoto, which is based on adding potassium 2,4-dihydroxy-6-carboxy-1,3,5-triazine (oxonate potassium) in the reaction system of the crude XO to obtain the same uric acid to be measured. ${ }^{13}$

\section{Statistical analyses}

Statistical analyses were performed by two-tailed Student's $t$-test or one-way analysis of variance (ANOVA) when appropriate. A nonparametric chi-square test was used to compare the sex frequencies. Bivariate correlation analysis was carried out using Pearson's or Spearman's correlation coefficients, appropriately. The association analysis was evaluated by odds ratio (OR) and corresponding $95 \%$ confidence interval $(95 \% \mathrm{CI})$, using the 90 th percentile in the unexposed to pesticides control group as cut-off levels. A pooled estimate of the common OR and its confidence interval was 
obtained by the Mantel-Haenszel method. Statistical analyses were performed with SPSS software version 16.0 (SPSS Inc., Chicago, IL, USA). $P$ values $<0.05$ were considered statistically significant.

\section{Results}

The clinical and demographic characteristics of patients and controls are shown in Table 1.

As indicated, age, sex, and body mass index were not different between the two patient groups and between patients and controls (for all comparisons, $P>0.05$ ). $\mathrm{LDH}$ and ALP levels were significantly increased in exposed and unexposed patients compared with controls (for the two comparisons, $P<0.05$ ); they were similar in both patient groups (respectively, $P=0.944$ and $P=0.841$ ). In addition, NLR levels were significantly increased in patients compared with controls and in exposed patients compared with in those not exposed and in controls (one-way ANOVA, $P<0.01$ ).
The serum levels of NADPH and IFN- $\gamma$, IL-4, and Th1/ Th2 ratio are shown in Figures 1 and 2, respectively.

Serum NADPH levels were significantly increased in patients compared with controls and in exposed patients compared with in those not exposed and in controls (one-way ANOVA; $P=0.000)$. IFN- $\gamma$ and the Th1/Th2 ratio were significantly decreased in patients when compared with controls; IL-4 was significantly increased (for all comparisons, oneway ANOVA; $P=0.000$ ).

As indicated in Table 2, albumin, GSH-Px, SOD, CAT, and ORAC levels were significantly decreased in patients compared with controls. ORAC levels were significantly decreased in exposed compared with in unexposed patients $(P=0.039)$. However, MDA levels were significantly increased in exposed patients when compared with controls and unexposed patients (one-way ANOVA; $P=0.000$ ). Protein carbonyl and XO levels were significantly increased in exposed patients compared with controls (comparison not

Table I Clinical and demographic characteristics of patients with NHL

\begin{tabular}{|c|c|c|c|c|c|}
\hline \multirow[t]{2}{*}{ Variables } & \multicolumn{2}{|l|}{$\begin{array}{l}\text { Controls } \\
n=40\end{array}$} & \multicolumn{2}{|l|}{$\begin{array}{l}\text { Patients } \\
n=100\end{array}$} & \multirow[t]{2}{*}{$P^{\mathrm{b}}$} \\
\hline & $\begin{array}{l}\text { Exposed controls } \\
n=20\end{array}$ & $\begin{array}{l}\text { Not exposed controls } \\
n=20\end{array}$ & $\begin{array}{l}\text { Exposed patients } \\
n=32\end{array}$ & $\begin{array}{l}\text { Not exposed patients } \\
n=68\end{array}$ & \\
\hline Age (year) & $56.12 \pm 2.93$ & $56.6 \pm 3.1$ & $58.48 \pm 3.27$ & $55.25 \pm 2.82$ & 0.901 \\
\hline $\mathrm{Pa}$ & 0.911 & & 0.492 & & \\
\hline $\operatorname{Sex}(M / F)$ & $12 / 8$ & $11 / 9$ & $18 / 14$ & $35 / 33$ & 0.911 \\
\hline$P a$ & 0.749 & & 0.817 & & \\
\hline BMI $\left(\mathrm{kg} / \mathrm{m}^{2}\right)$ & $22.84 \pm 0.64$ & $22.45 \pm 0.55$ & $22.53 \pm 0.76$ & $22.2 \pm 0.5$ & 0.920 \\
\hline$P a$ & 0.647 & & 0.713 & & \\
\hline LDH (U/L) & $208.73 \pm 57.29$ & $194.42 \pm 59.74$ & $498.72 \pm 75.77$ & $489.24 \pm 84.6 \mathrm{I}$ & 0.049 \\
\hline$P^{a}$ & 0.865 & & 0.944 & & \\
\hline ALP (U/I00 mL) & $87.25 \pm|3.4|$ & $83.57 \pm 14.13$ & $|36.54 \pm| 6.54$ & $|32.7| \pm 10.47$ & 0.021 \\
\hline$P a$ & 0.850 & & $0.84 I$ & & \\
\hline NLR & $1.82 \pm 0.09$ & $1.76 \pm 0.06$ & $2.34 \pm 0.03$ & $2.16 \pm 0.06$ & 0.000 \\
\hline $\mathrm{Pa}$ & 0.582 & & 0.000 & & \\
\hline NHL type & - & & & & \\
\hline B-cell NHL & - & & 84.38 & 86.76 & - \\
\hline$P a$ & - & & 0.748 & & \\
\hline T-cell NHL & - & & 15.63 & 13.24 & - \\
\hline$P a$ & - & & 0.748 & & \\
\hline Clinical stage & - & & & & \\
\hline CS I (\%) & - & & 40.63 & 42.65 & - \\
\hline$P^{\mathrm{a}}$ & - & & 0.848 & & \\
\hline CS II (\%) & - & & 21.88 & 20.59 & - \\
\hline$P a$ & - & & 0.883 & & \\
\hline CS III (\%) & - & & 25 & 22.06 & - \\
\hline$P^{a}$ & - & & 0.744 & & \\
\hline CS IV (\%) & - & & 12.5 & $|4.7|$ & - \\
\hline $\mathrm{Pa}$ & - & & 0.767 & & \\
\hline
\end{tabular}

Notes: $P<0.05$ was considered statistically significant. Data are presented as mean \pm standard error. Student's $t$-test; $P$ a: exposed controls versus not exposed controls or exposed patients versus not exposed patients, one-way ANOVA; Pb: comparison between the four groups.

Abbreviations: ALP, alkaline phosphatase; ANOVA, analysis of variance; BMI, body mass index; CS, clinical stage; F, female; LDH, lactate dehydrogenase; M, male; NHL, non-Hodgkin lymphoma. 


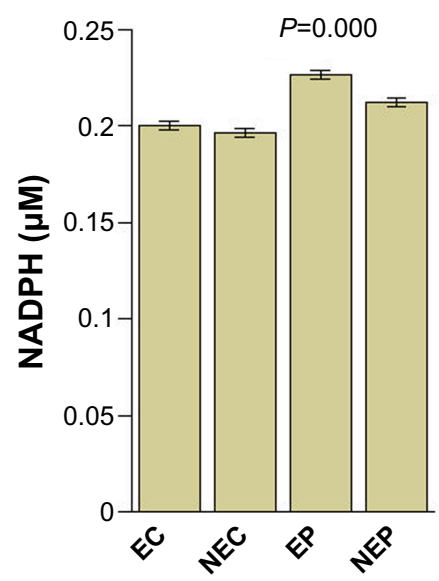

Figure I Mean levels of serum NADPH.

Abbreviations: NADPH, nicotinamide adenine dinucleotide phosphate hydrogen; EC, exposed controls; NEC, unexposed controls; EP, exposed patients; NEP, un exposed patients.

shown); there were no significant differences between the two patient groups or between unexposed patients and controls (for all comparisons, $P>0.05$ ).

We report in Figure 3 that NADPH was strongly associated with NHL, either in patients exposed or unexposed to pesticides (respectively, OR $=6.63$ [95\% CI, 1.91-23; $P=0.002] ;$ OR $=4.75$ [95\% CI, 1.27-17.72; $P=0.014]$; Mantel-Haenszel common OR estimate $=5.55[95 \%$ CI, 2.22-13.88; $P=0.000])$.

As shown in Figure 4, NADPH levels were significantly negatively related to the Th1/Th2 ratio, either in patients who have been exposed or not to pesticides (respectively, $r=-0.498, P=0.004$; and $r=-0.327 ; P=0.006$ ).

\section{Discussion}

One of the main biomarker indicators of the cancer process is the increased levels of ALP (EC 3.1.3.1), an enzyme that can be found at particularly high levels in the blood when bone-forming cells are very active. Its elevation is also observed in solid cancer metastasis, as with colorectal cancer. ${ }^{14}$ Our results are in agreement with those reporting an increase in ALP levels in patients with NHL or malignant cancer. ${ }^{15,16}$ ALP can also serve as a useful prognostic marker for malignant tumors, ${ }^{17}$ perhaps, given its role in removing phosphate groups from many kinds of molecules, including nucleotides.

The NLR has been recently reported to be a new potential predictor of systemic inflammation that is associated with outcome in different cancer types. Its elevation has also been demonstrated to be a poor prognostic factor in multiple types of malignancies, especially solid tumors. ${ }^{18}$ This ratio is used in cancer patients to compare the inflammatory response by counting neutrophils and evaluation of host immunity by counting lymphocytes. The increased level of NLR observed in the current study is consistent with other results. ${ }^{19}$ Nevertheless, to our best knowledge, we show for the first time the highest increase in NLR levels in patients with NHL exposed to pesticides.

The link between cancer and altered metabolism has previously been suggested as a common feature of cancerous tissues, such as the Warburg effect. ${ }^{20} \mathrm{~A}$ key molecule produced as a result of altered cancer metabolism is NADPH. This molecule is used in protective mechanisms against oxidative stress and ROS that are produced during rapid cell proliferation. However, to our best knowledge, there have been no studies that correlate NADPH to NHL. For our part, we have revealed a strong association between NADPH and NHL, either in patients exposed or not to pesticides; nevertheless, the association in patients exposed to pesticides was more significant compared with in those not exposed to pesticides.

To maintain a continuous and rapid cell division, cancer cells use a very large amount of energy, required for the
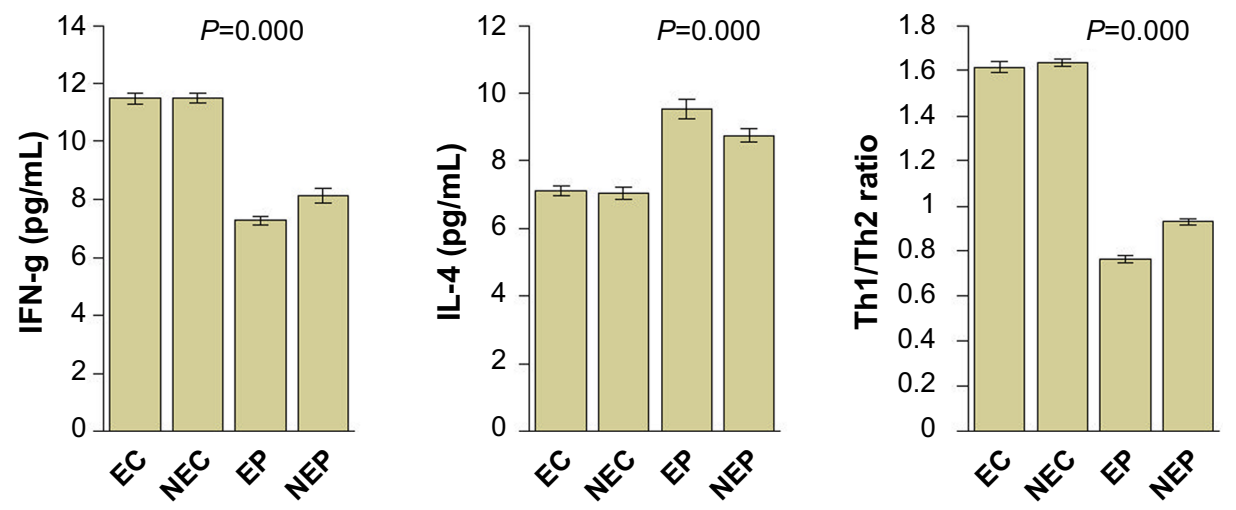

Figure 2 Circulating levels of IFN-g and IL-4, and ThI/Th2 ratio. Abbreviations: IFN-g, interferon-gamma; IL, interleukin; EC exposed controls; NEC, unexposed controls; EP, exposed patients; NEP, unexposed patients; Th, T helper. 
Table 2 Oxidative stress biomarkers in patients with $\mathrm{NHL}$ and controls

\begin{tabular}{|c|c|c|c|c|c|}
\hline \multirow[t]{2}{*}{ Variable } & \multicolumn{2}{|l|}{$\begin{array}{l}\text { Controls } \\
n=40\end{array}$} & \multicolumn{2}{|l|}{$\begin{array}{l}\text { Patients } \\
n=100\end{array}$} & \multirow[t]{2}{*}{$P^{b}$} \\
\hline & $\begin{array}{l}\text { Exposed controls } \\
n=20\end{array}$ & $\begin{array}{l}\text { Not exposed controls } \\
n=20\end{array}$ & $\begin{array}{l}\text { Exposed patients } \\
n=32\end{array}$ & $\begin{array}{l}\text { Not exposed patients } \\
n=68\end{array}$ & \\
\hline Albumin (g/L) & $34.85 \pm 0.75$ & $35.69 \pm 0.68$ & $28.22 \pm 0.61$ & $29.43 \pm 0.5$ & 0.000 \\
\hline$P^{a}$ & 0.412 & & 0.153 & & \\
\hline GSH-Px (IU/mL) & $1.83 \pm 0.1$ & $\mathrm{I} .77 \pm 0.08$ & $\mathrm{I} .5 \mathrm{I} \pm 0.08$ & $1.58 \pm 0.06$ & 0.038 \\
\hline$P a$ & 0.644 & & 0.516 & & \\
\hline $\operatorname{SOD}(\mathrm{U} / \mathrm{mL})$ & $84.68 \pm 1.12$ & $83.97 \pm 1.19$ & $78.16 \pm 1.3$ & $80.25 \pm 1.05$ & 0.006 \\
\hline Pa & 0.666 & & 0.242 & & \\
\hline CAT (IU/mL) & $22,101.29 \pm 402.27$ & $22,153.66 \pm 392.95$ & 20,774.32 & $20,645.94 \pm 336.22$ & 0.023 \\
\hline$P^{a}$ & 0.926 & & 0.543 & & \\
\hline ORAC (AU) & $2.25 \pm 0.08$ & $2.42 \pm 0.06$ & $1.66 \pm 0.06$ & $1.82 \pm 0.04$ & 0.000 \\
\hline$P^{a}$ & 0.099 & & 0.039 & & \\
\hline $\mathrm{MDA}(\mu \mathrm{mol} / \mathrm{L})$ & $2.37 \pm 0.07$ & $2.32 \pm 0.08$ & $2.88 \pm 0.07$ & $2.7 I \pm 0.05$ & 0.000 \\
\hline$P^{a}$ & $0.64 I$ & & 0.047 & & \\
\hline PC (nmol/mg protein) & $0.18 \pm 0.05$ & $0.15 \pm 0.04$ & $0.25 \pm 0.03$ & $0.22 \pm 0.02$ & 0.189 \\
\hline$p^{a}$ & 0.640 & & 0.395 & & \\
\hline $\mathrm{XO}(\mathrm{mlU} / \mathrm{mL})$ & $0.34 \pm 0.04$ & $0.31 \pm 0.05$ & $0.46 \pm 0.03$ & $0.43 \pm 0.03$ & 0.044 \\
\hline $\mathrm{Pa}$ & 0.638 & & 0.476 & & \\
\hline
\end{tabular}

Notes: $P<0.05$ was considered statistically significant. Data are presented as mean \pm standard error. Student's $t$-test; $P$ a: exposed controls versus not exposed controls or exposed patients versus not exposed patients, one-way ANOVA; $P$ : comparison between the four groups.

Abbreviations: ANOVA, analysis of variance; CAT, catalase; GSH-Px, glutathione peroxidase; MDA, malondialdehyde; NHL, non-Hodgkin lymphoma; ORAC, oxygen radical absorbance capacity/total antioxidant capacity; PC, protein carbonyl; SOD, superoxide dismutase; XO, xanthine oxidase.

biosynthesis of macromolecules (nucleotides, proteins, and lipids). The energy used for cell division, but also for the metastatic process and tightened maintenance of appropriate cellular redox, is provided mainly by glycolysis, which results in the formation of nucleotides, lactate, and ATP. ${ }^{21}$

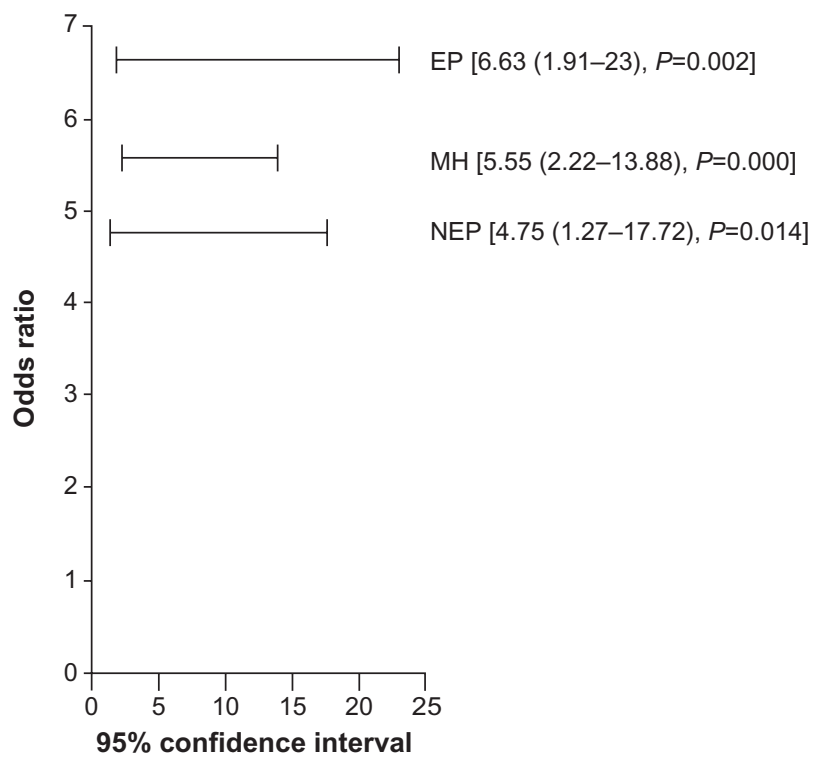

Figure 3 Association analysis of NADPH with non-Hodgkin lymphoma among patients exposed or not to pesticides.

Abbreviations: EP, exposed patients; NEP, unexposed patients; $\mathrm{MH}$, MantelHaenszel common odds ratio estimate; NADPH, nicotinamide adenine dinucleotide phosphate hydrogen.
The persistence of cell division is provided by a variety of molecular mechanisms, including the Warburg effect. Otto Warburg reported that cancer cells depend on glycolysis to predominantly produce energy, even with the presence of oxygen at normal concentrations, leading to the production of high levels of lactate. ${ }^{20}$ Unlike normal cells that produce energy from mitochondrial oxidative phosphorylation, without production of lactate, the Warburg effect leads to the production of huge amounts of lactate, which contributes to the phenomenon of microenvironmental acidosis. ${ }^{21}$ This effect is regulated by the PI3K, hypoxia-inducible factor, $\mathrm{p} 53$, avian myelocytomatosis virus oncogene cellular homolog (protooncogene homologous to myelocytomatosis virus, MYC) and 5' adenosine monophosphate-activated protein kinase (AMPK) B1 pathways. To the fact that the production of ATP through glycolysis is faster than by oxidative phosphorylation, cancer cells adopt mechanisms for absorbing abnormally high quantities of glucose to respond to increased requirements of energy, biosynthesis, and redox..22

The lactate produced in cancer cells by the Warburg effect, as a result of enhanced aerobic glycolysis, is provided from the conversion of pyruvate with $\mathrm{LDH} .{ }^{23}$ It is extruded through the extracellular space, via the monocarboxylate transporter 1 in endothelial cells, ${ }^{24}$ to the aerobic populations of cancer cells, where it may be used to power the Krebs cycle to produce energy. ${ }^{25}$ Lactate activates proinflammatory pathways ${ }^{26}$ and 

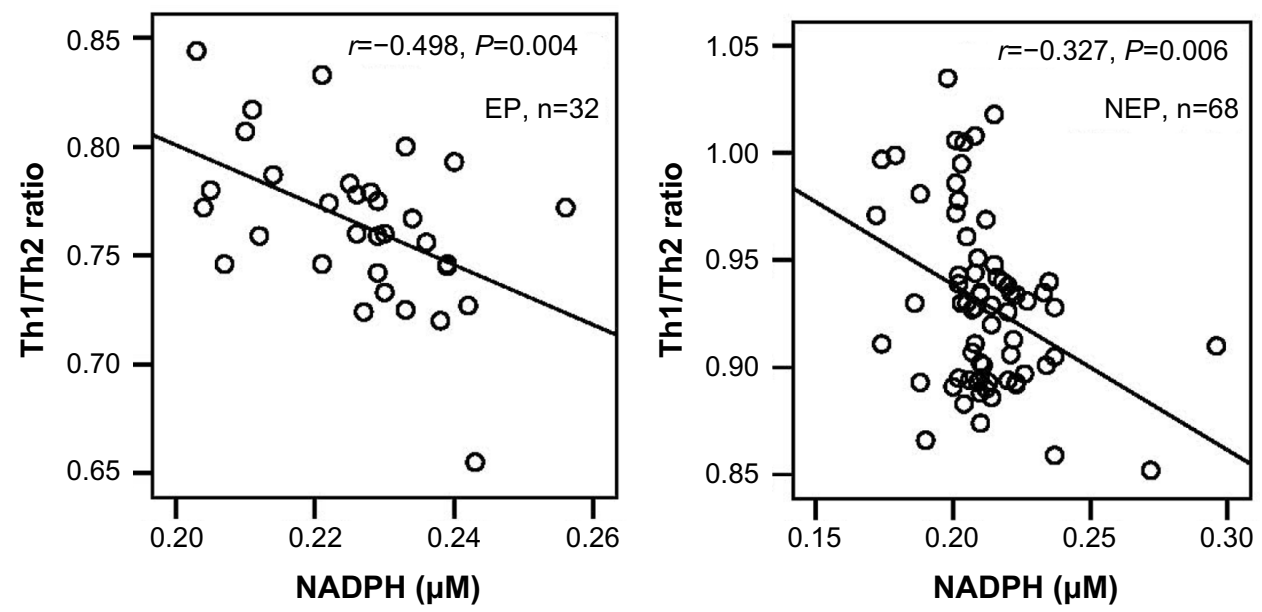

Figure 4 Relationship between NADPH and ThI/Th2 ratio in patients with NHL.

Abbreviations: EP, exposed patients; NEP, unexposed patients; Th, T helper; NADPH, nicotinamide adenine dinucleotide phosphate hydrogen; NHL, non-Hodgkin lymphoma.

enhances angiogenesis, which is essential for cancer growth and metastasis. ${ }^{24}$ Higher circulating LDH in cancer patients may be a result of increased damaged cells in response to many conditions, such as tissue injury, necrosis, hypoxia, and hemolysis. ${ }^{27}$ Our study is consistent with recent results. ${ }^{28,29}$

During the rapid proliferation, cancer cells displayed increased ROS. ${ }^{30}$ Cells can use their reactivity beneficially in many processes. Thus, a useful level of ROS is maintained within the cell by means of a balance between the production of a free radicals system (XO), antioxidant systems (SOD, GSH-Px, CAT, protein carbonyl, albumin), and ORAC. CAT reduces peroxides, GSH-Px protects cells against free radicals, and SOD catalyzes the conversion of two superoxide anions into a molecule of hydrogen peroxide $\left(\mathrm{H}_{2} \mathrm{O}_{2}\right)$ and oxygen. ${ }^{31}$ In our study, we observed an imbalance between the oxidants and antioxidants shifted toward the oxidant side in patients with NHL. Recent studies have shown increased oxidative stress in hematologic malignancies; ${ }^{32,33}$ nevertheless, little is known about oxidative stress biomarkers in NHL. During oxidative stress, ROS can induce increased production of byproduct mutagenic reagents, such as MDA. Our results are thus consistent with previously reported observations. ${ }^{34}$ In addition, it was shown that the overall antioxidant capacity, as measured by ORAC, decreases in patients with hematologic malignancies, especially in patients with NHL, ${ }^{35}$ which corroborates our results. Moreover, the increased levels of MDA and the decreased levels of ORAC were significantly pronounced in patients exposed to pesticides compared with those not exposed. Therefore, it has been reported that oxidative stress can be induced by pesticides, either by overproduction of free radicals or by alteration in antioxidant defense mechanisms. ${ }^{36}$
Interestingly, high levels of ROS can cause damage to macromolecules, which can induce apoptosis and senescence. ${ }^{22}$ For this reason, cancer cells adapt to metabolic changes that may affect the redox balance. Thus, unlike normal cells, cancer cells produce large quantities of NADH, $\mathrm{H}+$, which is consumed in an LDH step of glycolysis reaction in favor of the Warburg effect, with the aim of energy gain through oxidation to form three ATP molecules per each NADH, $\mathrm{H}+.^{21}$ In addition, these cells are able to extend beyond the Warburg effect as a result of an altered metabolism to meet its needs for macromolecule building blocks and maintenance of redox balance. Therefore, the NADPH can be generated by the cancer cells to act as a powerful antioxidant against ROS. ${ }^{37}$ This coenzyme is produced in two separate steps in the hexose monophosphate (HMP) shunt pathway. ${ }^{38}$ These data are consistent with our findings regarding the increased levels of NADPH in patients compared with controls. In our study, we also observed that the levels of oxidative stress biomarkers and NADPH are much more increased in patients exposed to pesticides compared with in those not exposed to pesticides and in control subjects. We therefore suggest that the increase in ROS levels generated by rapid cell proliferation and environmental toxicity would be continuously monitored by the production of NADPH.

Our results regarding the decrease in IFN- $\gamma$ levels and the increase of those of IL-4 shifted toward a decrease in the Th1/Th2 ratio. It has been reported that IFN- $\gamma$ is important for control of tumor growth and invasion and has been implicated in several cancers. ${ }^{39}$ In addition, it has previously been shown that the increase in levels of IL-4 is involved in tumor development. ${ }^{40}$ IL-4 can block the activation of natural killer cells and reduces the antigen 
formation of tumor cells to escape cytoimmunity against tumor growth. ${ }^{41}$ Moreover, imbalance in the ratio of Th1/ Th2 could play an important role in the etiology of NHL and its major subtypes. ${ }^{42}$ Although correlation does not imply causation, the negative relationship highlighted in the current study between NADPH and Th1/Th2 ratio would be in favor of an increased immunosuppressive effect of IL-4 on Th1 cells. A cause-and-effect relationship involving IL-4 and a pentose phosphate pathway required to generate NADPH has already been demonstrated in the mechanisms of macrophage polarization. ${ }^{43}$ In addition, it has previously been shown that IL-4 mediates B-cell survival by increasing glucose transport and glycolysis in B cells through Stat6-dependent upregulation of Bcl-xL. ${ }^{44}$ It was proven later that poly(ADP-ribose)polymerase 14, a member of the $\mathrm{B}$ aggressive lymphoma family of macrodomain-containing poly(ADP-ribose)polymerases, is needed to achieve full prosurvival signaling by IL-4 in B cells. ${ }^{45}$ In addition, IL-4 may be important in promoting glucose uptake and metabolism, which can be metabolized by the pentose phosphate pathway and required to promote T-cell proliferation and survival. ${ }^{46}$ Finally, the negative relationship between NADPH and Th1/Th2 ratio would also be in favor of lower antitumor effects of IFN $-\gamma \cdot{ }^{47}$ Therefore, it has been recently reported that NK cell IFN-gamma production could be directly related to mammalian target of rapamycin complex 1 and glycolysis. ${ }^{48}$ Moreover, it has been shown that lactic acid dramatically impairs IFN- $\gamma$ production in human cytotoxic $\mathrm{T}$ lymphocytes and number of IFN- $\gamma$-positive cells measured by flow cytometry. ${ }^{49}$

\section{Conclusion}

In conclusion, our results demonstrate for the first time that pesticide exposure was strongly associated with NADPH alteration in NHL. The examination of the relationship between NADPH and the Th1/Th2 ratio should focus on new therapeutic strategies to prevent the appearance of the disease. In addition, treatment strategies should also take into account exposure to pesticides as an important risk factor for disease development and adapt care and monitoring of patients.

\section{Acknowledgments}

We are grateful to the patients and subjects for their participation and are especially thankful to all the staff of the Clinical Haematology Departments of Tlemcen and Sidi Bel-Abbès Medical Centre University for their help during this study. We also thank Fethi Borsali (Faculty of Medicine, University of Tlemcen), for help with the statistical analysis, and Julian Ian Mitchell (University of Portsmouth, United Kingdom), who assisted in the proofreading of the manuscript.

\section{Disclosure}

The authors report no conflicts of interest in this work.

\section{References}

1. Vilchez RA, Madden CR, Kozinetz CA, et al. Association between simian virus 40 and non-Hodgkin lymphoma. Lancet. 2002;359(9309): $817-823$.

2. Chatenoud L, Bach JF. Immunology. Paris: Flammarion MedicineSciences; 2008.

3. von Stackelberg K. A systematic review of carcinogenic outcomes and potential mechanisms from exposure to 2,4-D and MCPA in the environment. J Toxicol. 2013;2013:371610.

4. Boccolini PM, Boccolini CS, Chrisman JR, et al. Pesticide use and non-Hodgkin's lymphoma mortality in Brazil. Int J Hyg Environ Health. 2013;216(4):461-466.

5. Agopian J, Navarro JM, Gac AC, et al. Agricultural pesticide exposure and the molecular connection to lymphomagenesis. $J$ Exp Med. 2009;206(7):1473-1483.

6. Kirsch M, De Groot H. NAD(P)H, a directly operating antioxidant? FASEB J. 2001;15(9):1569-1574.

7. Sato M, Goto S, Kaneko R, Ito M, Sato S, Takeuchi S. Impaired production of Th1 cytokines and increased frequency of Th2 subsets in PBMC from advanced cancer patients. Anticancer Res. 1998;18(5D): 3951-3955.

8. Cortes J, Kurzrock R. Interleukin-10 in non-Hodgkin's lymphoma. Leuk Lymphoma. 1997;26(3-4):251-259.

9. Paglia DE, Valentine WN. Studies on the quantitative and qualitative characterization of erythrocyte glutathione peroxidase. J Lab Clin Med. 1967;70(1):158-169.

10. Aebi H. Catalase. In: Bergmeyer HU, editor. Methods of Enzymatic Analysis. New York: Academic Press; 1974:673-684.

11. Blache D, Durand P, Prost M, Loreau N. (+)-Catechin inhibits platelet hyperactivity induced by an acute iron load in vivo. Free Radic Biol Med. 2002;33(12):1670-1680.

12. Nourooz-Zadeh J, Tajaddini-Sarmadi J, Ling KL, Wolff SP. Low-density lipoprotein is the major carrier of lipid hydroperoxides in plasma. Relevance to determination of total plasma lipid hydroperoxide concentrations. Biochem J. 1996;313(Pt 3):781-786.

13. Hashimoto $S$. A new spectrophotometric assay method of xanthine oxidase in crude tissue homogenate. Anal Biochem. 1974;62(2):426-435.

14. Saif MW, Alexander D, Wicox CM. Serum Alkaline Phosphatase Level as a Prognostic Tool in Colorectal Cancer: A Study of 105 patients. J Appl Res. 2005;5(1):88-95.

15. Kittivorapart J, Chinthammitr Y. Incidence and risk factors of bone marrow involvement by non-Hodgkin lymphoma. J Med Assoc Thai. 2011;94(Suppl 1):S239-S245.

16. Tardivon AA, Vanel D, Munck JN, Bosq J. Magnetic resonance imaging of the bone marrow in lymphomas and leukemias. Leuk Lymphoma. 1997;25(1-2):55-68.

17. Yu MC, Chan KM, Lee CF, et al. Alkaline phosphatase: does it have a role in predicting hepatocellular carcinoma recurrence? J Gastrointest Surg. 2011;15(8):1440-1449.

18. Chen C, Sun P, Dai QS, Weng HW, Li HP, Ye S. The Glasgow Prognostic Score predicts poor survival in cisplatin-based treated patients with metastatic nasopharyngeal carcinoma. PLoS One. 2014; 9(11): e112581.

19. Porrata LF, Ristow K, Habermann T, Inwards DJ, Micallef IN, Markovic SN. Predicting survival for diffuse large B-cell lymphoma patients using baseline neutrophil/lymphocyte ratio. Am J Hematol. 2010;85(11):896-899. 
20. Warburg O. On the origin of cancer cells. Science. 1956;123(3191): 309-314.

21. El Sayed SM, Mahmoud AA, El Sawy SA, et al. Warburg effect increases steady-state ROS condition in cancer cells through decreasing their antioxidant capacities (anticancer effects of 3-bromopyruvate through antagonizing Warburg effect). Med Hypotheses. 2013;81(5):866-870.

22. Cairns RA, Harris IS, Mak TW. Regulation of cancer cell metabolism. Nat Rev Cancer. 2011;11(2):85-95.

23. Colen CB, Shen Y, Ghoddoussi F, et al. Metabolic targeting of lactate efflux by malignant glioma inhibits invasiveness and induces necrosis: an in vivo study. Neoplasia. 2011;13(7):620-632.

24. Végran F, Boidot R, Michiels C, Sonveaux P, Feron O. Lactate influx through the endothelial cell monocarboxylate transporter MCT1 supports an NF- $\mathrm{KB} / \mathrm{IL}-8$ pathway that drives tumor angiogenesis. Cancer Res. 2011;71(7):2550-2560.

25. Semenza GL. Tumor metabolism: cancer cells give and take lactate. J Clin Invest. 2008;118(12):3835-3837.

26. Shime H, Yabu M, Akazawa T, et al. Tumor-secreted lactic acid promotes IL-23/IL-17 proinflammatory pathway. J Immunol. 2008;180(11): $7175-7183$.

27. Armstrong AJ, George DJ, Halabi S. Serum lactate dehydrogenase predicts for overall survival benefit in patients with metastatic renal cell carcinoma treated with inhibition of mammalian target of rapamycin. J Clin Oncol. 2012;30(27):3402-3407.

28. Koukourakis MI, Kontomanolis E, Giatromanolaki A, Sivridis E, Liberis V. Serum and tissue LDH levels in patients with breast/gynaecological cancer and benign diseases. Gynecol Obstet Invest. 2009;67(3) $162-168$.

29. Abdelrazik N, Fouda M, Zaghloul MH, Abbas D. Serum level of intercellular adhesion molecule-1 in children with malignant lymphoma. Med Princ Pract. 2008;17(3):233-238.

30. Aykin-Burns N, Ahmad IM, Zhu Y, Oberley LW, Spitz DR. Increased levels of superoxide and $\mathrm{H}_{2} \mathrm{O}_{2}$ mediate the differential susceptibility of cancer cells versus normal cells to glucose deprivation. Biochem $J$. 2009;418(1):29-37.

31. Trachootham D, Lu W, Ogasawara MA, Nilsa RD, Huang P. Redox regulation of cell survival. Antioxid Redox Signal. 2008;10(8) 1343-1374.

32. Pasanen AK, Kuitunen H, Haapasaari KM, et al. Expression and prognostic evaluation of oxidative stress markers in an immunohistochemical study of B-cell derived lymphomas. Leuk Lymphoma. 2012;53(4): 624-631.

33. Akinlolu A, Akingbola T, Salau B. Lipid peroxidation in Nigerians affected with haematological malignancies. Afr J Med Med Sci. 2012;41(Suppl):145-148.

34. Eissa LA, Esmaeel MI. Relevance of some serum biomarkers (E cadherin, GAGs and MDA in patients with diffuse large B-cell lymphoma. Pak J Pharm Sci. 2008;21(1):29-35.
35. Holtan SG, O'Connor HM, Fredericksen ZS, et al. Food-frequency questionnaire-based estimates of total antioxidant capacity and risk of non-Hodgkin lymphoma. Int J Cancer. 2012;131(5):1158-1168.

36. Mecdad AA, Ahmed MH, ElHalwagy MEA, Afify MMM. A study on oxidative stress biomarkers and immunomodulatory effects of pesticides in pesticide-sprayers. Egyptian J Forensic Sci. 2011;1(2):93-98.

37. Le A, Cooper CR, Gouw AM, et al. Inhibition of lactate dehydrogenase A induces oxidative stress and inhibits tumor progression. Proc Natl Acad Sci U S A. 2010;107(5):2037-2042.

38. Mayes PA, Bender DA. Overview of metabolism. In: Murray RK, Granner DK, Mayes PA, Rodwell VW, editors. Harper's Illustrated Biochemistry. 26th ed. New York: Lange Medical Books; 2003: 122-237.

39. Hayashi T, Horiuchi A, Sano K, et al. Potential role of LMP2 as tumorsuppressor defines new targets for uterine leiomyosarcoma therapy. Sci Rep. 2011;1:180.

40. Mellgren K, Hedegaard CJ, Schmiegelow K, Müller K. Plasma cytokine profiles at diagnosis in pediatric patients with non-hodgkin lymphoma. J Pediatr Hematol Oncol. 2012;34(4):271-275.

41. Shi H, Li W. Inhibitory effects of human lactoferrin on U14 cervical carcinoma through upregulation of the immune response. Oncol Lett. 2014;7(3):820-826.

42. Lan Q, Zheng T, Rothman N, et al. Cytokine polymorphisms in the Th1/Th2 pathway and susceptibility to non-Hodgkin lymphoma. Blood. 2006;107(10):4101-4108.

43. Haschemi A, Kosma P, Gille L, et al. The sedoheptulose kinase CARKL directs macrophage polarization through control of glucose metabolism. Cell Metab. 2012;15(6):813-826.

44. Dufort FJ, Bleiman BF, Gumina MR, et al. Cutting edge: IL-4-mediated protection of primary B lymphocytes from apoptosis via Stat6-dependent regulation of glycolytic metabolism. J Immunol. 2007;179(8): 4953-4957.

45. Cho SH, Ahn AK, Bhargava P, et al. Glycolytic rate and lymphomagenesis depend on PARP14, an ADP ribosyltransferase of the B aggressive lymphoma (BAL) family. Proc Natl Acad Sci U S A. 2011;108(38): 15972-15977.

46. Maciver NJ, Jacobs SR, Wieman HL, Wofford JA, Coloff JL, Rathmell JC. Glucose metabolism in lymphocytes is a regulated process with significant effects on immune cell function and survival. J Leukoc Biol. 2008;84(4):949-957.

47. Ikeda H, Old LJ, Schreiber RD. The roles of IFN gamma in protection against tumor development and cancer immunoediting. Cytokine Growth Factor Rev. 2002;13(2):95-109.

48. Donnelly RP, Loftus RM, Keating SE, et al. mTORC1-dependent metabolic reprogramming is a prerequisite for $\mathrm{NK}$ cell effector function. J Immunol. 2014;193(9):4477-4484.

49. Fischer K, Hoffmann P, Voelkl S, et al. Inhibitory effect of tumor cellderived lactic acid on human T cells. Blood. 2007;109(9):3812-3819.
Journal of Blood Medicine

\section{Publish your work in this journal}

The Journal of Blood Medicine is an international, peer-reviewed, open access, online journal publishing laboratory, experimental and clinical aspects of all topics pertaining to blood based medicine including but not limited to: Transfusion Medicine; Blood collection, Donor issues, Transmittable diseases, and Blood banking logistics; Immunohematology; Artificial and alternative

\section{Dovepress}

blood based therapeutics; Hematology; Biotechnology/nanotechnology of blood related medicine; Legal aspects of blood medicine; Historical perspectives. The manuscript management system is completely online and includes a very quick and fair peer-review system. Visit http://www.dovepress.com/ testimonials.php to read real quotes from published authors. 